\title{
A detailed Hapmap of the Sitosterolemia locus spanning 69 kb; differences between Caucasians and African-Americans

\author{
Bhaswati Pandit ${ }^{1,5}$, Gwang-Sook Ahn ${ }^{1,6}$, Starr E Hazard2, Derek Gordon ${ }^{3,7}$ \\ and Shailendra B Patel $* 1,4$
}

\begin{abstract}
Address: ${ }^{1}$ Division of Endocrinology, Diabetes and Medical Genetics, Medical University of South Carolina, STR 541,114 Doughty Street, Charleston, SC 29403, USA, 2Biomolecular Computing Resource, Medical University of South Carolina, STR 541, 114 Doughty Street, Charleston, SC 29403, USA, ${ }^{3}$ Lab of Statistical Genetics, Rockefeller University, 1230 York Avenue, NY 10021, USA, ${ }^{4}$ Division of Endocrinology, Metabolism \& Clinical Nutrition, Medical College of Wisconsin, 9200 West Wisconsin Avenue, E4950, Milwaukee, WI 53226, USA, ${ }^{5}$ Department of Human Genetics, Mount Sinai School of Medicine, New York, NY 10029, 'Department of Biology, College of Natural Science, Daejeon University, Daejeon 300-716, South Korea and ${ }^{7}$ Department of Genetics, Rutgers, The State University of New Jersey, 145 Bevier Road, Room 128, Piscataway, NJ 08854-8009
\end{abstract}

Email: Bhaswati Pandit - bhaswati.pandit@mssm.edu; Gwang-Sook Ahn - ahngs@dju.ac.kr; Starr E Hazard - Hazard@musc.edu; Derek Gordon - gordon@biology.rutgers.edu; Shailendra B Patel* - sbpatel@mcw.edu

* Corresponding author

Published: 28 February 2006

BMC Medical Genetics2006, 7:13 doi:10.1/86/147|-2350-7-13
Received: 25 October 2005

Accepted: 28 February 2006

This article is available from: http://www.biomedcentral.com/I47/-2350/7//3

(C) 2006Pandit et al; licensee BioMed Central Ltd.

This is an Open Access article distributed under the terms of the Creative Commons Attribution License (http://creativecommons.org/licenses/by/2.0), which permits unrestricted use, distribution, and reproduction in any medium, provided the original work is properly cited.

\begin{abstract}
Background: Sitosterolemia is an autosomal recessive disorder that maps to the sitosterolemia locus, STSL, on human chromosome 2p21. Two genes, ABCG5 and ABCG8, comprise the STSL and mutations in either cause sitosterolemia. $A B C G 5$ and $A B C G 8$ are thought to have evolved by gene duplication event and are arranged in a head-to-head configuration. We report here a detailed characterization of the STSL in Caucasian and African-American cohorts.
\end{abstract}

Methods: Caucasian and African-American DNA samples were genotypes for polymorphisms at the STSL locus and haplotype structures determined for this locus

Results: In the Caucasian population, 13 variant single nucleotide polymorphisms (SNPs) were identified and resulting in 24 different haplotypes, compared to II SNPs in African-Americans resulting in 40 haplotypes. Three polymorphisms in ABCG8 were unique to the Caucasian population (E238L, INT 10-50 and G575R), whereas one variant (A259V) was unique to the AfricanAmerican population. Allele frequencies of SNPs varied also between these populations.

Conclusion: We confirmed that despite their close proximity to each other, significantly more variations are present in $A B C G 8$ compared to $A B C G 5$. Pairwise $D^{\prime}$ values showed wide ranges of variation, indicating some of the SNPs were in strong linkage disequilibrium (LD) and some were not. LD was more prevalent in Caucasians than in African-Americans, as would be expected. These data will be useful in analyzing the proposed role of STSL in processes ranging from responsiveness to cholesterol-lowering drugs to selective sterol absorption. 


\section{Background}

Although our diets contain an equal amount of cholesterol and plant sterols, only $30-60 \%$ of cholesterol and less than $5 \%$ of total plant sterols are absorbed daily $[1,2]$. Additionally, of the small amounts of non-cholesterol sterols (primarily plant sterols) that are absorbed, these are preferentially excreted into bile by the liver, resulting in a very low level of whole-body retention [2]. In sitosterolemia, intestinal discrimination between cholesterol and non-cholesterol sterols and the ability of the liver to excrete normally all sterols (cholesterol and non-cholesterol sterols) are disrupted [3]. Thus, the defect in sitosterolemia defines the molecular mechanisms by which these processes take place.

We mapped the sitosterolemia disease to a single locus, STSL, to chromosome $2 \mathrm{p} 21$ in a region defined by the markers D2S2294 and Afm210xe9 [4-6]. This locus has now been shown to comprise of two highly homologous genes, ABCG5 and ABCG8, arranged in a head-to-head organization $[7,8]$. Two mutations in either both copies of ABCG5 or both copies of ABCG8 result in sitosterolemia [7-9]. To date, sitosterolemia has not been reported to be caused by a person harboring a mutation in one allele of
ABCG5 and one allele of ABCG8. These gene are expressed in a tissue-specific manner (liver and intestine only) and they are thought to function as obligate heterodimers [10]. Genetic analyses of STSL showed that despite their close proximity, $A B C G 8$ shows a much greater genetic variability than ABCG5 [8]. This disparate genetic evolution seems to be unique to humans, as the mouse and rat STSL loci show relatively equal extent of variations in $A b c g 5$ and $A b c g 8[11,12]$. At present, the implications of the relatively more conservation in ABCG5 compared to ABCG8 is not known. This seems remarkable, since both genes are highly homologous to each other, with preserved exonintron structures and are also highly conserved from Man to Fugu [12].

The human genome is arranged in an array of haplotype blocks (haploblocks), characterized by segments of high LD followed by regions of low LD [13-17]. Haploblocks may have arisen from recombination hotspots that are never divided during meiosis $[18,19]$ or may be randomly distributed due to uniform but rare recombination [20].

In this paper, we report the detailed characterization of the SNPs present at the STSL in Caucasians drawn from

Table I: Polymorphisms reported at the STSL locus

\begin{tabular}{|c|c|c|c|c|c|}
\hline Name & Position in the gene & Polymorphism & dbSNP cluster ID & $\begin{array}{l}\text { Restriction enzyme } \\
\text { site altered }\end{array}$ & Nucleotide Position \\
\hline \multicolumn{6}{|l|}{ ABCG5 } \\
\hline P9P & Exon I & $\mathrm{C} / \mathrm{T}$ & rs 49854016 & BstN I & 22881725 \\
\hline $\mathrm{R} 50 \mathrm{C}^{*}$ & Exon 2 & $\mathrm{C} / \mathrm{T}$ & rs6756629 & - & 22881023 \\
\hline V523I & Exon II & $\mathrm{G} / \mathrm{A}$ & ss 49854017 & - & 22863069 \\
\hline C600Y & Exon 13 & $\mathrm{G} / \mathrm{A}$ & ss49854018 & - & 22856345 \\
\hline Q604E* & Exon 13 & $\mathrm{G} / \mathrm{C}$ & rs6720173 & Sml I & 22856334 \\
\hline V622M & Exon 13 & G/A & ss498540I9 & - & 22856280 \\
\hline \multicolumn{6}{|l|}{ ABCG8 } \\
\hline 5' UTR-4I & 5' UTR & $\mathrm{C} / \mathrm{T}$ & ss 49854020 & BstE II & 22882085 \\
\hline 5' UTR-19* & 5' UTR & $\mathrm{T} / \mathrm{G}$ & rs380647 I & Tsp45 I & 22882107 \\
\hline PI7P & Exon I & $\mathrm{G} / \mathrm{C}$ & ss4985402I & - & 22882176 \\
\hline $\mathrm{DI} 9 \mathrm{H}^{*}$ & Exon I & $\mathrm{G} / \mathrm{C}$ & rs I I 887534 & - & 22882180 \\
\hline INTI-2I* & Intron I & $\mathrm{C} / \mathrm{A}$ & ss4|48209 & Mnl I & 22887558 \\
\hline INTI-7* & Intron I & $\mathrm{C} / \mathrm{T}$ & ss4 $1482 \mid 10$ & BsmA I & 22887572 \\
\hline $\mathrm{C} 54 \mathrm{Y}^{*}$ & Exon 2 & $\mathrm{G} / \mathrm{A}$ & ss4 I 482 I I & SexA I & 22887676 \\
\hline E238L* & Exon 6 & $\mathrm{G} / \mathrm{A}$ & ss49854010 & - & 22895692 \\
\hline $\mathrm{A} 259 \mathrm{~V} *$ & Exon 6 & $\mathrm{C} / \mathrm{T}$ & ss 49854012 & Hae III & 22895756 \\
\hline Q340E & Exon 7 & $C / G$ & ss49854024 & - & 22915101 \\
\hline $\mathrm{T} 400 \mathrm{~K}^{*}$ & Exon 8 & C/A & ss4 | 482 I 7 & Mse I & 22915366 \\
\hline M429V & Exon 9 & $\mathrm{G} / \mathrm{A}$ & & - & 22916932 \\
\hline INT9-19 & Intron 9 & $\mathrm{C} / \mathrm{T}$ & ss49854025 & - & 22917460 \\
\hline INTI0-50* & Intron 10 & $\mathrm{C} / \mathrm{T}$ & ss4| 48220 & - & 22918168 \\
\hline A565A* & Exon II & $\mathrm{C} / \mathrm{T}$ & ss4| | 4822 | & - & 22918424 \\
\hline G575R* & Exon II & $\mathrm{G} / \mathrm{C}$ & rs495840II & Hha I & 22918452 \\
\hline $\mathrm{A} 632 \mathrm{~V} *$ & Exon 13 & $\mathrm{C} / \mathrm{T}$ & rs65447I8 & Sty I & 22920858 \\
\hline
\end{tabular}

*Only these SNPs were found to be variant in the present study and the haplotypes (See Table 2 and 3 ) are ordered with these reported in sequence. The SNPs shown in bold (4th column) are ones that also part of the HapMap dataset. Nucleotide numbering according to GenBank Sequence ID NT 022184. 
Table 2: Estimated haplotype frequencies for Caucasians

\begin{tabular}{|c|c|c|}
\hline Haplotype* & Est. Freq. & Cum. Freq. \\
\hline 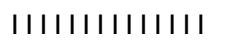 & 0.229 & 0.229 \\
\hline 11111111121111 & 0.224 & 0.453 \\
\hline 11111121111111 & 0.083 & 0.536 \\
\hline 11211121111111 & 0.063 & 0.599 \\
\hline 11111121121111 & 0.042 & $0.64 I$ \\
\hline 21111111121111 & 0.031 & 0.672 \\
\hline 21212221111112 & 0.031 & 0.703 \\
\hline 11111121111112 & 0.031 & 0.734 \\
\hline 11212221111111 & 0.031 & 0.766 \\
\hline 211222211111111 & 0.016 & 0.781 \\
\hline 21112111121112 & 0.016 & 0.797 \\
\hline 21211221112111 & 0.016 & 0.813 \\
\hline 11211121111211 & 0.016 & 0.828 \\
\hline 11212211112111 & 0.016 & 0.844 \\
\hline 21112221121111 & 0.016 & 0.859 \\
\hline $11 \mid 12122112112$ & 0.016 & 0.875 \\
\hline 12121111111112 & 0.016 & 0.891 \\
\hline 11111121112112 & 0.016 & 0.906 \\
\hline 22111111121111 & 0.016 & 0.922 \\
\hline 11112121121111 & 0.016 & 0.938 \\
\hline 11112221111112 & 0.016 & 0.953 \\
\hline 21212221121212 & 0.016 & 0.969 \\
\hline 11211111111122 & 0.016 & 0.984 \\
\hline 11112111111111 & 0.016 & 1.000 \\
\hline
\end{tabular}

*The left to right order of the haplotype reports on the asterisked SNPs shown top to bottom in Table I.

our cohort of sitosterolemia families, as well as a group of African-American individuals who were normal and healthy. These data allows us to characterize this locus in detail and define some of these haploblocks. Preliminary reports have implicated STSL in physiological processes ranging from responsiveness to 'statin' drugs used to lower plasma cholesterol, as well as more complex processes such as the metabolic syndrome [21-29]. The data reported herein should allow for a more detailed and definitive testing of these hypotheses.

\section{Methods}

\section{SNP analyses}

All studies were performed after Institutional Review Board approval and with informed consent of the participants. Genomic DNA was isolated from blood obtained from Caucasian patients and their family members as previously described [8]. African-American DNA samples came from the ongoing Sea Islands Families Project/ Project Sugar at the Medical University of South Carolina $[30,31]$. These individuals are part of the larger Gullahspeaking ethnic community who were born and reared in the coastal Sea Islands of Georgia, South Carolina and North Carolina, and whose parents were also reared on the Sea Islands. In the Project Sugar protocols, Type 2 diabetic probands are identified and then phenotypic data and DNA are obtained from the proband and the
A.
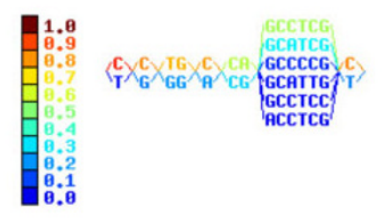

B.

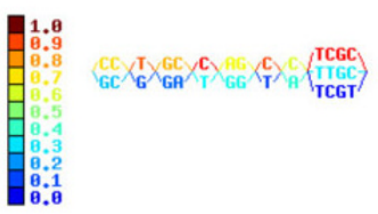

Figure I

Haploblock structure of STSL in Caucasians and in African-Americans. Haploblocks were constructed as described in Methods. The color bars indicate the frequencies with which each of the haploblock sequences are found. Note the larger haploblock arrangements in Caucasians (panel A), compared to that observed in African-Americans (panel B).

proband's family members. This database was screened for all individuals who were not diabetic and unrelated to each other to obtain a total of 46 unrelated individuals. Each exon and boundary intronic area of ABCG5 and ABCG8 was amplified by specific primers as previously described and SNPs detected by restriction enzyme digestion patterns $[5,8]$ or by the primer extension method, using a capillary DNA analyzer (CEQ 8000, Beckman Coulter, Fullerton, CA). For the latter, amplified PCR products were digested with two units of Shrimp alkaline phosphatase (SAP, Roche Chemicals) and one unit of Exonuclease I (New England Biolabs, Ipswich, MA) at $37^{\circ} \mathrm{C}$ for one hour to remove unused primers and unincorporated nucleotides. The enzymes were inactivated by treating the samples at $75^{\circ} \mathrm{C}$ for $15 \mathrm{~min}$. A primer extension reaction was set up using cleaned PCR products as template, the downstream primer adjacent to the SNP and fluorescent dideoxynucleotides. Multiplex extension reactions were carried out in some cases (details available on request). Samples were analyzed using a genetical analyzer, CEQ800 using the manufacturer's SNP separation method. Based upon the measured frequencies of each allele, observed genotypes were compared to expected genotypes for deviation from the Hardy-Weinberg principle. $\mathrm{X}^{2}$ values were calculated by comparing the observed and expected genotype frequencies using the formula $\Sigma$ (observed-expected value) ${ }^{2} /$ Expected value. P value was obtained from the $\mathrm{X}^{2}$ value table. The Age of mutation fixation was calculated as described by Guo and Xiong [32]. We selected 12 parents (24 chromosomes) carrying the commonest mutation, W361X, and where complete genotype information was available to compute recombination frequencies.

\section{Haplotype analyses}

Genotyping data were used to estimate haplotypes using SNPHAP program [33], PHASE v2.1 [34] and haploblocks 
Table 3: Estimated haplotype frequencies for African-Americans

\begin{tabular}{|c|c|c|}
\hline Haplotype* & Est. Freq & Cum Freq \\
\hline 1111112111111 & 0.099 & 0.099 \\
\hline 11111221121111 & 0.076 & 0.175 \\
\hline 11111121111211 & 0.071 & 0.246 \\
\hline 11111111111211 & 0.070 & 0.316 \\
\hline 11111111121111 & 0.059 & 0.376 \\
\hline 11111121121111 & 0.054 & 0.430 \\
\hline 11\|\|\|\|\|\|\|\| & 0.041 & 0.471 \\
\hline 11111221111111 & 0.034 & 0.505 \\
\hline 21111211121111 & 0.030 & 0.535 \\
\hline 21112221111111 & 0.030 & 0.564 \\
\hline 21111121121111 & 0.028 & 0.592 \\
\hline 12121221111111 & 0.022 & 0.614 \\
\hline 21212111111211 & 0.022 & 0.636 \\
\hline $1121 I I I I I I I 2 I I$ & 0.022 & 0.657 \\
\hline 11121121221111 & 0.022 & 0.679 \\
\hline 21111111121211 & 0.022 & 0.701 \\
\hline 21111121111211 & 0.021 & 0.721 \\
\hline 21111211111111 & 0.020 & 0.742 \\
\hline 11112121121111 & 0.016 & 0.757 \\
\hline 21111211111211 & 0.015 & 0.772 \\
\hline 11112211111111 & 0.012 & 0.785 \\
\hline 21111111121111 & 0.012 & 0.797 \\
\hline 11211221211111 & 0.011 & 0.808 \\
\hline 11211121111111 & 0.011 & 0.818 \\
\hline 11221121111211 & 0.011 & 0.829 \\
\hline $1|2| I 2 \mid I I I I I I I$ & 0.011 & 0.840 \\
\hline 11211211111211 & 0.011 & 0.851 \\
\hline 11112121221111 & 0.011 & 0.862 \\
\hline $1 I I 2 I I I I I I I I I I$ & 0.011 & 0.873 \\
\hline 11111221211211 & 0.011 & 0.884 \\
\hline 11112121111112 & 0.011 & 0.895 \\
\hline 11221111111211 & 0.011 & 0.905 \\
\hline 11111221121211 & 0.011 & 0.916 \\
\hline 21121121111111 & 0.011 & 0.927 \\
\hline 11111211221111 & 0.011 & 0.938 \\
\hline 21112121221211 & 0.011 & 0.949 \\
\hline 21112121211211 & 0.011 & 0.960 \\
\hline 11211211211111 & 0.011 & 0.971 \\
\hline 21111221111112 & 0.011 & 0.982 \\
\hline 21122211111111 & 0.011 & 0.992 \\
\hline
\end{tabular}

*The left to right order of the haplotype reports on the asterisked SNPs shown top to bottom in Table I.

were constructed using HaploBlockFinder v6 [35]. Linkage disequilibrium measures [36], $\mathrm{D}^{\prime}$ and $\Delta^{2}$, were estimated between pairs of diallelic loci using the value of Lewontin's D' [37] and measured using the GOLD program [38].

\section{Results}

Our study consists of 32 parents (obligate carriers for mutations in either ABCG5 or ABCG8) of Caucasian origin from around the world [8]. Our African-American cohort consists of 46 unrelated individuals from the Sea Island community around South Carolina. Table 1 lists 23 SNPs ( 6 in ABCG5 and 17 in ABCG8) identified by exten- sive re-sequencing at the STSL locus by us, or those reported in the literature. The SNPS will be referred to as either by the amino acid they affect, or by their relative position in the gene. A formal identification for each of these SNPs is provided in Table 1. Only two loci in ABCG5, R50C and Q604E showed variations in our study population, the remaining 4 SNPs were invariant in all subjects and are not depicted in the haplotype analyses. For $A B C G 8$, only 12 variable loci were identified, marked by an asterisk, Table 1 , the remaining were non-variant in our study samples. All of the SNPs shown in Table 1 except M429V in ABCG8 were analyzed. M429V was reported only recently in a Japanese cohort [29], and was not included for analyses in this study. However, in limited analyses, we did not detect this in any of our previously sequenced exon 9 DNA traces either (data not shown), suggesting it may have a very low prevalence. Thus, only 14 SNPs (asterisked, Table 1) constitute the haplotypes shown and are ordered with $A B C G 5$, followed by $A B C G 8$.

The A259V polymorphism was present only in AfricanAmericans. The C/T polymorphism at INT10-50 position, E238L and G575R in ABCG8 were variable only in the Caucasians. The haplotypes shown comprise all of the marked loci in both groups (Table 1) in order. Among the unrelated parents (Caucasians) all the SNPs, except R50C were in Hardy-Weinberg Equilibrium ( $p>0.005, \chi$ Square test). To completely characterize the haplotype structure, we estimated haplotype frequencies in each sample population using the multi-locus genotype data for each sample population. Estimates of haplotype frequencies are presented in Tables 2 and 3 for the Caucasians and African-Americans, respectively. These frequencies were estimated using the method described by Excoffier and Slatkin [33] as implemented in the SNPHAP program (Electronic Database Information).

The frequencies of the minor alleles varied from 0.02632 to 0.5 shown by different color code in Fig. 1 . Twenty-four haplotypes were constructed from 64 chromosomes with the SNP signature CCTGCCGGCCTCGC haplotype as the most common among Caucasians, accounting for $~ 23 \%$ of the haplotypes (Table 2). For SNPs that affect amino acids, this translates to E604-R50-D19-C54-E238-A259T400-A565-G575-A632. The next common Caucasian haplotype differs from this one in that there is a lysine at position 400 in ABCG8 (K400) and these two haplotypes account for $\sim 45 \%$ of all haplotypes. There were many minor haplotypes whose contribution was very low (Table 2). The haplotypes were divided into seven blocks. The haplotype data is summarized in Table 2.

In the case of African-Americans, we identified four SNPs whose prevalence deviated significantly from Hardy- 


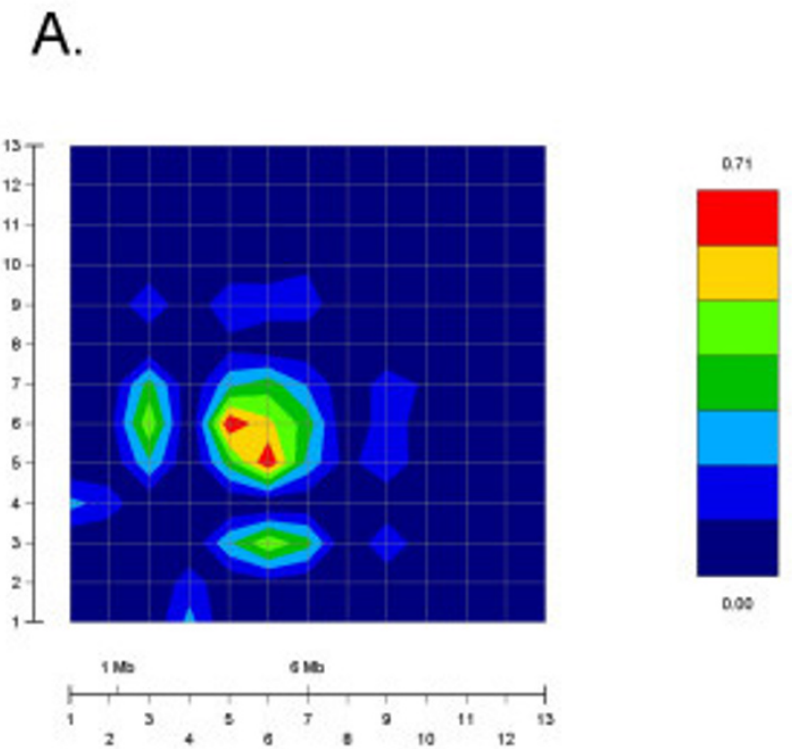

\section{B.}

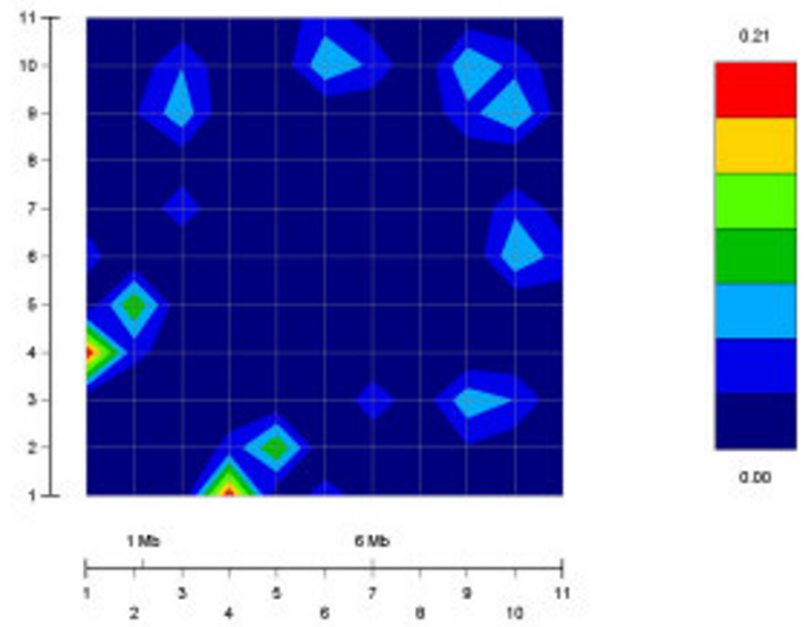

Figure 2

GOLD plot of pair-wise $\Delta^{2}$ values for SNPs in Caucasians and African-Americans. As a pictorial depiction of LD at the STSL, GOLD plots for Caucasians (panel A) and African-Americans (panel B) were plotted. Note the differences in the color scales between the two panels shown on the right-hand side of each plot. Overall, a small area of LD was present in the Caucasian sample, as shown by the increased red intensity, almost all of this was accounted for an area involving intron I. For African-Americans, very little LD was present (compare the GOLD plots with Table 4).

Weinberg equilibrium (5' UTR-19, D19H, A259V, A565A) all of which are located in ABCG8. Minor allele frequencies varied from 0.02174 to 0.38043 . Haplotypes were divided into eight blocks as shown in Fig. 2. Additionally, a SNP that results in A259V in ABCG8 was detected in this cohort, but was absent in Caucasians, and a SNP that was variant in Caucasian (E238L in ABCG8) but was non-variant in African-Americans. The cumulative frequency shown (Table 3) does not sum to 1 in the African-American sample population. We deleted from the list of haplotypes those whose estimated frequencies were less than $1 /$ $(2 \times 46) \sim 0.00107$, since there are only 92 total haplotypes in all 46 individuals. Forty haplotypes were constructed, of which the signature CCTGCCGGCCTCGC was the major haplotype ( $~ 9.9 \%)$, translating to a coding haplotype of E604-R50-D19-C54-E238-A259-T400A565-G575-A632, identical to the commonest Caucasian haplotype. However, the second commonest haplotype in Caucasians, with the K400 change was not detected at all in the African-Americans. Note the large numbers of haplotypes with the lower frequencies detected in the AfricanAmericans, compared to the Caucasian samples.

Table 4 presents results of pair-wise linkage disequilibrium (LD) analysis for the fourteen SNPs at the STSL locus in these two populations (African-American and Cauca- sian). In this table, we present the pair of loci considered (columns labeled M1 and M2), the value of the Chisquare statistic (column labeled ChiSq) that tests whether $D^{\prime}$ (a measure of LD [37]) is non-zero, the p-value corresponding to the Chi-square statistic (column labeled Pval), and estimates of two measures of linkage disequilibrium, $\Delta^{2}[36]$ and $D^{\prime}$ [37]. Both measures of linkage disequilibrium range between 0 and 1,0 meaning no LD and 1 meaning complete disequilibrium. Although we computed LD values for $\left(\begin{array}{c}14 \\ 2\end{array}\right)=91$ pairs of markers, we present results only for those pairs whose p-value for the Chi-square statistic is less than 0.10 in the interest of consolidation of results. Pair-wise LD was calculated using GOLD program (Fig. 2, regions red in color indicate high LD values). Caucasians (Fig. 2A) appear to have larger pair-wise $\Delta^{2}$ for consecutive markers more frequently than do African-Americans (Fig. 2B). Of note, for the non-synonymous SNPs, R50C and D19H showed some LD in both populations, though the Ch-square statistic was only moderate (Table 4). Amongst Caucasians, the strongest LD was observed between the two intronic SNPs, INT1-12 
A.

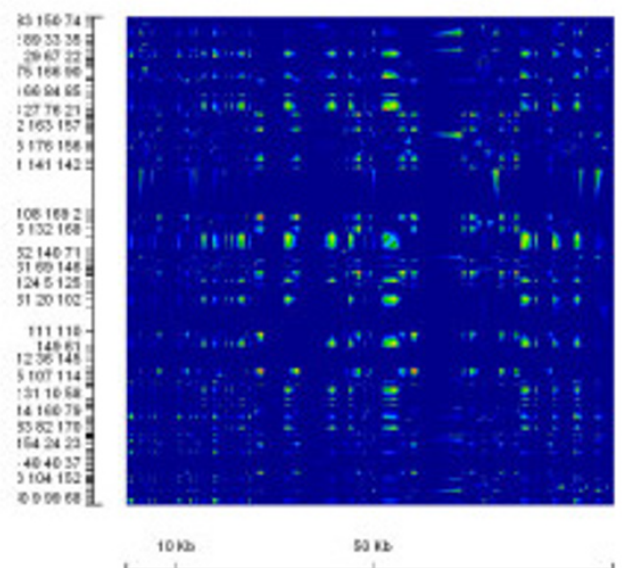

B.

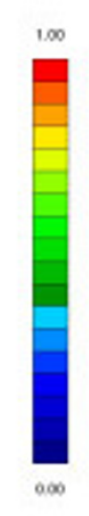

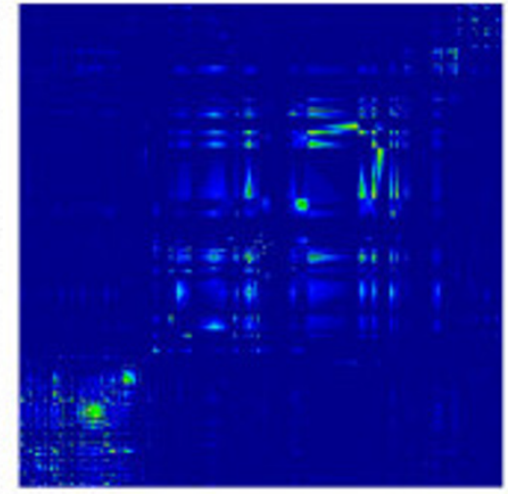

$\sin$

$3 n$

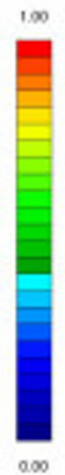

Figure 3

GOLD plot of pair-wise $\Delta^{2}$ values for SNPs in CEPH and Yoruba Africans genotyped by the HapMap Consortium. We analyzed the SNP genotypes spanning the STSL locus for the CEPH (panel A) and Yoruba (panel B) samples available at http://www.hapmap.org. The HapMap SNP dataset are much more dense. Note that the Yoruba samples show very little LD compared to the Caucasian samples. Additionally, the Caucasian samples also show that the STSL locus does not have any large segments of LD.

and INT1-7, and to a lesser extent between INT1-7 and both 5'UTR-19 and Q604E (Table 4).

With the publication of the HapMap data during the preparation and submission of this manuscript [39], we were able to compare our data with that of the HapMap data (available at [40]). We compared data for SNPs typed on chromosome 2, between positions $44,012,000$ to $44,081,000$, containing the STSL locus. The GOLD plots for Caucasian samples (CEPH family data) and African samples (Yoruba samples from Nigeria) are shown in Fig. 3. The HapMap data for this region is much denser. Additionally, there are some significant differences between SNPs used in our study and those reported by the HapMap Consortium. Firstly, of the 14 SNPs we found were variant in our entire cohort, only 8 of these were also genotyped by the HapMap Consortium, highlighted in Table 1. Secondly, of the 6 that are unique to our genotyping, 5 of these are cSNPs and are all non-synonymous changes, and the $6^{\text {th }}$, INT1-21, was one where we detected significant LD for Caucasian samples (See Fig. 2A). Of the remaining 9 SNPs we genotyped and found no variants (Table 1), with the exception of M429V, which we did not genotype, the HapMap Consortium also do not report any genotyping data. It is not clear to us whether this is because they also failed to show these were variant, or because these were not tested. Nevertheless, given the richness of the HapMap dataset, we present the Haploview analyses (which allows for a better pictorial representation than GOLD for large data sets) for these two populations (Fig. 4), which are essentially the screenshots available at their website [40], with some image cropping for presentation. Note that there are 2 hot-spots of recombination that can be identified and these are located at the ends of both ABCG5 and ABCG8 (Fig. 4). Despite differences highlighted between the HapMap Data and ours, the overall conclusions are similar; in both analyses, the samples originating in peoples from Africa show the least amount of linkage disequilibrium, the greatest variability and smaller haploblocks (data not shown), compared to Caucasian samples. The differences between our samples may also be significant. Our Caucasian samples are drawn from families with sitosterolemia and come from many different parts of the World. Our African-American samples, while maintaining a much closer genetic tie to Africa, are drawn from peoples from a variety of Africans originating from West Africa, not just the Yoruba, in Nigeria [30].

Age of mutation was calculated considering W361X as the most common disease causing mutation. Table 5 summarizes the data linking the estimated age of mutation with the alleles. Of the non-synonymous cSNPs, T400K of ABCG8 was found to be oldest polymorphism that arose 
Table 4: Results of pair-wise LD analyses

\begin{tabular}{|c|c|c|c|c|c|c|}
\hline Population & MI & $M 2$ & ChiSq & Pval & $\Delta^{2}$ & $D^{\prime}$ \\
\hline \multirow[t]{18}{*}{ Caucasian } & INTI-2I & INTI-7 & 20.01 & IE-05 & 0.545 & 0.866 \\
\hline & 5'UTR-19 & INTI-7 & 9.61 & 0.002 & 0.256 & 0.594 \\
\hline & Q604E & INTI-7 & 7.14 & 0.008 & 0.239 & 0.489 \\
\hline & $\mathrm{T} 400 \mathrm{~K}$ & $\mathrm{~A} 632 \mathrm{~V}$ & 6.13 & 0.013 & 0.125 & 1.000 \\
\hline & 5'UTR- 19 & $\mathrm{~T} 400 \mathrm{~K}$ & 5.84 & 0.016 & 0.153 & 1.000 \\
\hline & Q604E & $\mathrm{DI} 9 \mathrm{H}$ & 5.02 & 0.025 & 0.174 & 1.000 \\
\hline & INTI-7 & T400K & 4.94 & 0.026 & 0.111 & 1.000 \\
\hline & R50C & $\mathrm{DI} 9 \mathrm{H}$ & 4.79 & 0.029 & 0.234 & 0.484 \\
\hline & INTI-2I & T400K & 4.45 & 0.035 & 0.153 & 1.000 \\
\hline & E238L & INTI0-50 & 4.42 & 0.036 & 0.238 & 1.000 \\
\hline & INTI-7 & C54Y & 4.41 & 0.036 & 0.138 & 0.739 \\
\hline & 5'UTR-19 & C54Y & 4.24 & 0.040 & 0.134 & 0.619 \\
\hline & T400K & INTIO-50 & 3.92 & 0.048 & 0.040 & 1.000 \\
\hline & 5'UTR-19 & $\mathrm{A} 565 \mathrm{~A}$ & 3.86 & 0.049 & 0.127 & 1.000 \\
\hline & Q604E & INTI-2I & 3.66 & 0.056 & 0.128 & 0.420 \\
\hline & INTI0-50 & $\mathrm{A} 632 \mathrm{~V}$ & 3.29 & 0.070 & 0.132 & 0.641 \\
\hline & 5'UTR- 19 & INTI-2I & 2.86 & 0.091 & 0.071 & 0.267 \\
\hline & C54Y & T400K & 2.74 & 0.098 & 0.082 & 0.433 \\
\hline \multirow[t]{11}{*}{ African-American } & 5'UTR-19 & $\mathrm{T} 400 \mathrm{~K}$ & 11.01 & $9 \mathrm{E}-04$ & 0.080 & 1.000 \\
\hline & INTI-7 & A565A & 8.09 & 0.004 & 0.085 & 0.587 \\
\hline & R50C & $\mathrm{DI} 9 \mathrm{H}$ & 6.96 & 0.008 & 0.205 & 1.000 \\
\hline & $\mathrm{T} 400 \mathrm{~K}$ & A565A & 6.56 & 0.010 & 0.088 & 0.557 \\
\hline & Q604E & INTI-2I & 5.82 & 0.016 & 0.119 & 0.505 \\
\hline & 5'UTR-19 & A565A & 5.10 & 0.024 & 0.059 & 0.460 \\
\hline & C54Y & A565A & 3.93 & 0.047 & 0.053 & 0.270 \\
\hline & 5'UTR-19 & C54Y & 3.49 & 0.062 & 0.047 & 0.481 \\
\hline & $\mathrm{R} 50 \mathrm{C}$ & INTI-7 & 3.05 & 0.081 & 0.044 & 1.000 \\
\hline & INTI-7 & $\mathrm{A} 632 \mathrm{~V}$ & 3.05 & 0.081 & 0.044 & 1.000 \\
\hline & Q604E & $\mathrm{DI} 9 \mathrm{H}$ & 3.01 & 0.083 & 0.038 & 1.000 \\
\hline
\end{tabular}

$M I=\left.\right|^{\text {st }}$ marker in pair of SNPs, M2 = 2nd marker in pair of SNPs, ChiSq $=$ Value of chi-square test of association, Pval = Two-sided P-value corresponding to chi-square value in ChiSq column assuming I degree of freedom.

$\Delta^{2}=$ Estimated value of Delta-squared measure of LD.

$D^{\prime}=$ Estimated value of Lewontin's [37] measure of LD.

about 2387 generations ago $(\sim 47,000 \mathrm{y})$. This SNP was also closely spaced to W361X mutation. The youngest cSNPS was estimated to be 180 y old (C54Y). The only cSNP we could estimate by this methodology in ABCG5 was Q604E ( $\sim 4,000$ y old). We could not estimate the ages in some of the SNPs due to insufficient information to allow us to estimate recombination frequencies (indicated by NA, Table 5).

\section{Discussion}

There are several reports correlating defects in a polygenic disease with single nucleotide changes in the coding or regulatory regions. SNPs also offer a substantial advantage in linkage disequilibrium-based studies of disease gene mapping [41], pharmacogenetics [42] and human evolution [43]. Studies of African, Asian and European Caucasian populations have shown that both a dense marker set, as well as larger sample size will be needed for a stable fine-scale depiction of haploblocks [44,45]. Variations in $A P O D$ gene were associated with an increased risk of early onset of Alzheimer's disease in a group of Finns [46]. Responses to pharmacotherapy also vary from person to person and in part can be accounted for by genetic variations and haplotype structures [47]. Thus characterization of SNPs, as well as the haploblock structures will be useful in defining the roles of genes in health and disease. We have characterized SNPs present at the STSL locus in Caucasian families with sitosterolemia and in a group of normal healthy African-Americans. This locus is important as its disruption leads to the human disorder, sitosterolemia [3]. More importantly, this locus comprises of two genes, ABCG5 and ABCG8, which are critical in handling of dietary sterols and for biliary sterol excretion [48]. Thus they are important in whole body sterol balance and have been implicated in cardiovascular health. A number of studies have been implicated this locus in disease (or physiologi- 
Table 5: Estimation of age of polymorphism fixation.

\begin{tabular}{|c|c|c|c|c|c|c|c|}
\hline SNP & Allele & $\begin{array}{l}\text { Number of } \\
\text { Disease } \\
\text { Chromosomes* }\end{array}$ & $\begin{array}{l}\text { Number of } \\
\text { Healthy } \\
\text { Chromosomes* }\end{array}$ & $\begin{array}{c}\text { Frequency } \\
\text { (disease } \\
\text { chromosome) }\end{array}$ & $\begin{array}{c}\text { Frequency } \\
\text { (healthy } \\
\text { chromosome) }\end{array}$ & $\begin{array}{l}\text { Recombination } \\
\text { Fraction }\end{array}$ & $\begin{array}{l}\text { Age Estimate } \\
\text { (generations) }\end{array}$ \\
\hline $\mathrm{R} 50 \mathrm{C}$ & C & 12 & 12 & 1 & I & NA & \\
\hline Q604E & G & 2 & I & 0.167 & 0.083 & 0.058833 & 17.7 \\
\hline 5'UTR-19 & $\mathrm{T}$ & 11 & 10 & 0.917 & 0.833 & 0.033059 & 9.1 \\
\hline DI9H & G & 12 & 12 & I & I & NA & NA \\
\hline INTI-2I & C & 12 & 7 & I & 0.583 & 0.005 & 0 \\
\hline INTI-7 & C & 11 & 11 & 0.917 & 0.917 & NA & \\
\hline C54Y & $A$ & 9 & 5 & 0.75 & 0.417 & 0.02749 & 8.8 \\
\hline E238L & G & 12 & 12 & I & 1 & NA & \\
\hline T400K & $A$ & 10 & 3 & 0.833 & 0.25 & 0.0002 & 2387 \\
\hline INTIO-50 & $T$ & 12 & 12 & I & I & NA & \\
\hline A565A & C & 12 & 12 & I & I & NA & \\
\hline G575R & G & 12 & 12 & I & I & NA & \\
\hline A632V & $C$ & II & 10 & 0.917 & 0.833 & 0.005692 & 52.9 \\
\hline
\end{tabular}

*Out of a total of 12 disease and 12 normal chromosomes, see Methods

cal) processes ranging from lipoprotein kinetics [22], cholesterol absorption $[27,29]$, obesity [27] to response to drug therapy [26].

When performing power and sample size calculations for disease or QTL genetic association, a critical parameter is some measure of linkage disequilibrium between the trait and marker locus [49-52]. Because the trait locus is unobserved, this parameter is usually unknown. A surrogate measure is some average marker-marker linkage disequilibrium measure [53]. Our work determining markermarker linkage disequilibrium for SNPs in the ABCG5/ $A B C G 8$ gene cluster will enable researchers to perform more realistic power and sample size calculations for genetic association studies involving the ABCG5/ABCG8 cluster. Prior to placing these studies in context of the data reported herein, there are some important points that need highlighting about our study. While this manuscript was in submission, the HapMap data were reported [39]. This latter dataset is not only more dense, it examined 4 different populations. The Chinese and Japanese samples show significantly more LD over this area, with much larger haploblock structures than the Yoruba and the CEPH populations (data not show, but available at [40]). These data are in keeping with our analyses of the high degree of homozygosity for markers spanning the STSL locus in families with sitosterolemia originating from Japan or China [5]. However, comparison of the SNPs we genotyped to those in the HapMap dataset showed that a significant number of cSNPs we genotyped were not analyzed in the HapMap dataset (see Table 1). Additionally, one cSNP, M429V, which was reported to be relatively more frequent in the Japanese population [29], was also absent from the HapMap dataset analyzing the Chinese Han and the Tokyo Japanese DNA samples. Thus our analyses presented herein add to this body of knowledge.
We noted a number of differences between the Caucasian and African-American populations. Some of these are expected. For example, the African-American population sampled contains many more variations and haplotypes. Additionally, the haploblock structures were smaller and the extent of linkage disequilibrium between markers was lower, in keeping with the Out-of-Africa theory for the origins of humans. This was true for both our dataset as well as analyses of the HapMap dataset. Some exceptions are notable. SNPs in intron 1 of ABCG8 show some linkage to a common non-synonymous SNP, Q604E, in ABCG5, but present in exon 13 (almost $20 \mathrm{~kb}$ apart). It is not clear if the intronic variations have a regulatory effect on transcription, but these data draw attention to this possibility. The transcriptional regulation of STSL remains poorly characterized, with few definitive studies to indicate which regulatory transcriptional factors, as well as nucleotide sequences are involved.

Four SNPs, 5' UTR-19, D19H, A259V, and A565A, in ABCG8 were not in Hardy-Weinberg equilibrium for the African-Americans. One explanation is sampling error. Since the unrelated African-American samples were gleaned from a sample collected for the presence of diabetes and family members ascertained, it is possible that, despite genealogical screens to remove related samples etc., some non-randomness error has skewed the data. This error may be compounded by the small sample size. Another explanation is that there may be a selection process that has led to this. We favor the first explanation, although this issue will only be resolved with analyses of a much larger sample. Secondly, we confirm that despite the relative proximity of $A B C G 5$ to $A B C G 8$, there was significantly less variation observed for ABCG5 and would suggest some selection or difference in mutational rates and fixation between $A B C G 5$ and ABCG8. Since ABCG5 


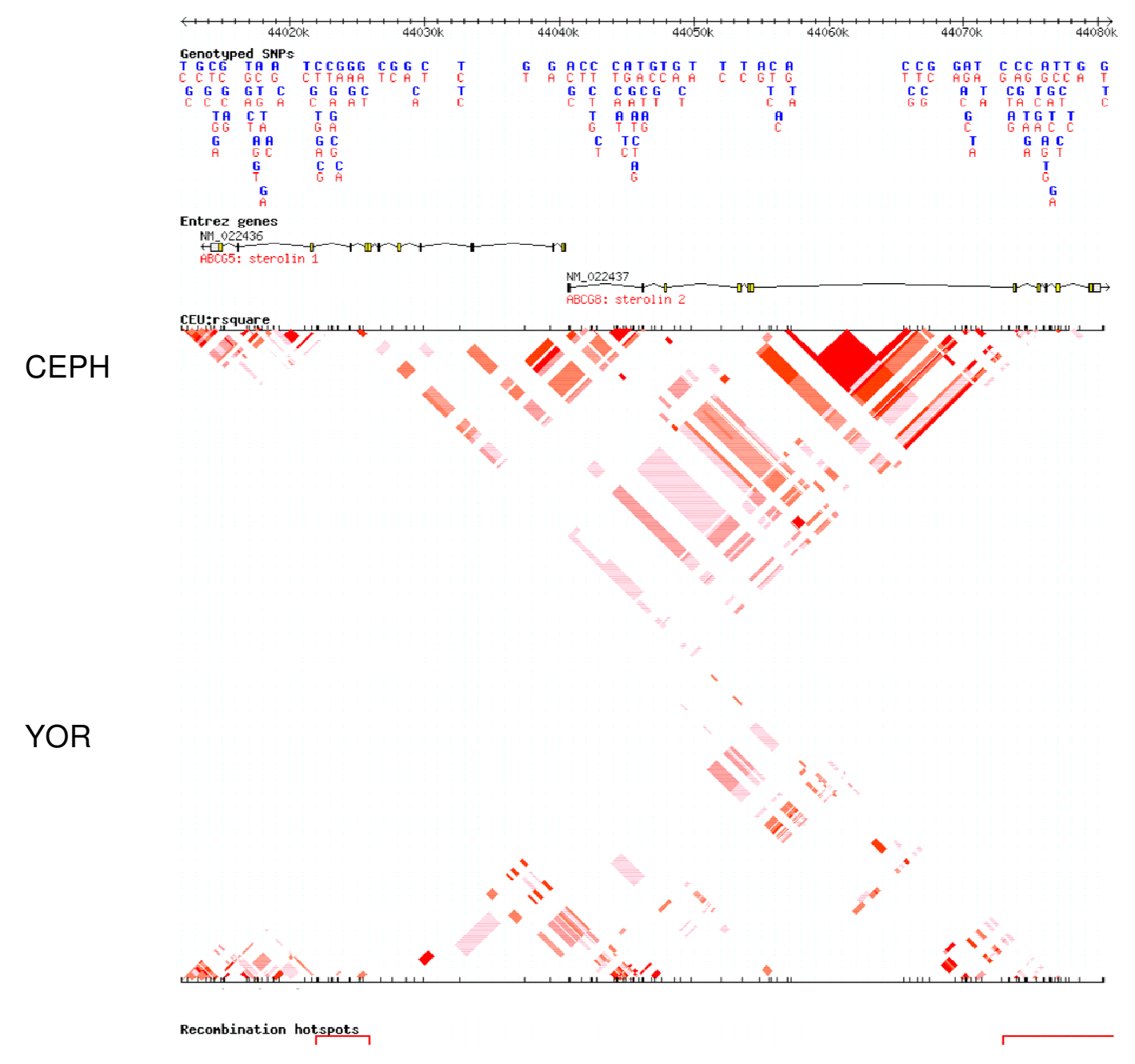

\section{Figure 4}

Haploview analyses of CEPH and Yoruba Africans genotyped by the HapMap Consortium. Using the data and analyses available at the website, http://www.hapmap.org, we selected the genotypes for the CEPH and Yoruba populations. The CEPH LD plot, using Haploview is shown above the Yoruba plot (inverted). As can be seen, for both, there is little evidence of significant LD for the SNP makers used. Additionally, two hotspots for recombination were identified (depicted by the red bars at the bottom of the picture), located at the ends of the STSL locus and involve the terminal exons of both ABCG5 and ABCG8 (which contain the transmembrane domains).

and $A B C G 8$ are proposed to function as obligate heterodimers [54], and complete mutations in either gene seems to result in an identical phenotype [8], these genetic findings posit an enigma. It is not clear what selective pressures may be responsible for this, if any. In rodents, almost equal variations are noted in Abcg5 and Abcg8 $[11,12]$. It will be of some interest to see if this difference in $A B C G 5 / A B C G 8$ variability is present in populations related to Man, such as Chimpanzees and other greater apes. We note that in the HapMap dataset, there are many more SNPs reported for ABCG5. However, all of these are exclusively located in the non-coding regions and, to date, there are more cSNPs in ABCG8 than there are in ABCG5. A number of association studies reporting linkage of cer- tain SNPs at the STSL locus to a number of seemingly unconnected phenotypes, ranging from response to a cholesterol-lowering drug, to insulin sensitivity and lipoprotein kinetics in obese subjects have been reported. Unfortunately, these do not intuitively allow for a selective advantage, positive or negative, that can explain the differences in the variability between ABCG5 and ABCG8.

Compared to other markers, SNPs have a lower mutation rate and are valuable for estimating age of mutations. SNPs in ABCG5 appear to be newly created compared to those in ABCG8. Additionally, in this study, we could not replicate the identification of other polymorphic variants in $A B C G 5$, including some we have reported previously 
[8]. These are P9P, V532I and V622M. This may reflect the rarity of these SNPs and our small sample size. If so, to investigate the role of these SNPs in biology may require a much larger sample size. Additionally, these SNPs may be race-related. For example, the M429V SNP was reported in the Japanese samples and seems to play a role in cholesterol absorption [29]. However, we were not able to detect this SNP in either the Caucasian or the AfricanAmerican samples. Additionally this SNP was also not reported in the Japanese and Chinese cohort in the HapMap dataset. Thus, this SNP may represent another racespecific polymorphism.

\section{Conclusion}

We report a detailed characterization of the STSL locus, present data that show regions of $\mathrm{LD}$ at this locus and provide data that should allow for more accurate Power calculations for studies examining the role of this locus in human biology. Our dataset has uniquely analyzed SNPS not reported in by the SNP consortium and therefore add to this knowledge base.

\section{Abbreviations}

ABC; ATP binding cassette, SNP; single nucleotide polymorphism. STSL; sitosterolemia locus.

\section{Competing interests}

The author(s) declare that they have no competing interests.

\section{Authors' contributions}

BP, G-SA, SEH, DG and SBP generated data and analyzed them. BP and SBP wrote the manuscript.

\section{Acknowledgements}

We wish to thank Drs. W. Timothy Garvey and David McLean, and all the participants of Project Sugar for allowing us access to the Gullah DNA samples. This work was supported by a grant from the National Institutes of Health, NHLBI, PHS HL0606I3 (SBP) and by the Daejeon University Research Fund of 2003 (G-SA).

\section{References}

I. Gould RG, Jones RJ, LeRoy GV, Wissler RW, Taylor CB: Absorbability of beta-sitosterol in humans. Metabolism 1969, I 8(8):652-662.

2. Salen G, Ahrens EJ, Grundy SM: Metabolism of beta-sitosterol in man. Journal of Clinical Investigation 1970, 49(5):952-967.

3. Bhattacharyya AK, Connor WE: Beta-sitosterolemia and xanthomatosis. A newly described lipid storage disease in two sisters. J Clin Invest 1974, 53(4): 1033-1043.

4. Patel SB, Salen G, Hidaka H, Kwiterovich PO, Stalenhoef AF, Miettinen TA, Grundy SM, Lee MH, Rubenstein JS, Polymeropoulos MH, Brownstein MJ: Mapping a gene involved in regulating dietary cholesterol absorption. The sitosterolemia locus is found at chromosome 2p2 I. J Clin Invest 1998, I02(5): I04 I-I044.

5. Lee MH, Gordon D, Ott J, Lu K, Ose L, Miettinen T, Gylling H, Stalenhoef $A F$, Pandya $A$, Hidaka $H$, Brewer JB, Kojima $H$, Sakuma $N$, Pegoraro R, Salen G, Patel SB: Fine mapping of a gene responsible for regulating dietary cholesterol absorption; founder effects underlie cases of phytosterolemia in multiple communities. Eur J Hum Genet 200I, 9:375-384.
6. Lu K, Lee MH, Carpten JD, Sekhon M, Patel SB: High-Resolution Physical and Transcript Map of Human Chromosome 2p2 I Containing the Sitosterolemia Locus. Eur J Hum Genet 200I, 9:364-374.

7. Berge KE, Tian H, Graf GA, Yu L, Grishin NV, Schultz J, Kwiterovich $\mathrm{P}$, Shan B, Barnes R, Hobbs $\mathrm{HH}$ : Accumulation of dietary cholesterol in sitosterolemia caused by mutations in adjacent $A B C$ transporters. Science 2000, 290(5497): I77I-I775.

8. Lu K, Lee MH, Hazard S, Brooks-Wilson A, Hidaka H, Kojima H, Ose L, Stanlenhoef AFH, Mietinnen T, Bjorkhem I, Brukert E, A. P, Brewer $H B$, Salen G, Dean M, Srivastava A, Patel SB: Two genes that map to the STSL locus cause sitosterolemia: Genomic structure and spectrum of mutations involving sterolin- $I$ and sterolin2, encoded by $\mathbf{A B C G 5}$ and $\mathbf{A B C G 8}$ respectively. Am J Hum Genet 200I, 69:278-290.

9. Lee MH, Lu K, Hazard S, Yu H, Shulenin S, Hidaka H, Kojima H, Allikmets R, Sakuma N, Pegoraro R, Srivastava AK, Salen G, Dean M, Patel $\mathrm{SB}$ : Identification of a gene, ABCG5, important in the regulation of dietary cholesterol absorption. Nature Genetics 200I, 27:79-83.

10. Graf GA, Li WP, Gerard RD, Gelissen I, White A, Cohen JC, Hobbs $\mathrm{HH}$ : Coexpression of ATP-binding cassette proteins ABCG5 and $A B C G 8$ permits their transport to the apical surface. Clin Invest 2002, I I 0(5):659-669.

I I. Lu K, Lee MH, Yu H, Zhou Y, Sandell SA, Salen G, Patel SB: Molecular cloning, genomic organization, genetic variations, and characterization of murine sterolin genes Abcg5 and Abcg8. J Lipid Res 2002, 43(4):565-578.

12. Yu H, Pandit B, Klett E, Lee MH, Lu K, Helou K, Ikeda I, Egashira N, Sato M, Klein R, Batta A, Salen G, Patel SB: The rat STSL locus: characterization, chromosomal assignment, and genetic variations in sitosterolemic hypertensive rats. BMC CardiovasC Disord 2003, 3(1):4

13. Gabriel SB, Schaffner SF, Nguyen H, Moore JM, Roy J, Blumenstiel B, Higgins J, DeFelice M, Lochner A, Faggart M, Liu-Cordero SN, Rotimi C, Adeyemo A, Cooper R, Ward R, Lander ES, Daly MJ, Altshuler D: The structure of haplotype blocks in the human genome. Science 2002, 296(5576):2225-2229.

14. Daly MJ, Rioux JD, Schaffner SF, Hudson TJ, Lander ES: High-resolution haplotype structure in the human genome. Nat Genet 200।, 29(2):229-232.

15. Goldstein DB: Islands of linkage disequilibrium. Nat Genet 200I, 29(2): |09-III.

16. Patil N, Berno AJ, Hinds DA, Barrett WA, Doshi JM, Hacker CR, Kautzer CR, Lee DH, Marjoribanks C, McDonough DP, Nguyen BT, Norris MC, Sheehan JB, Shen N, Stern D, Stokowski RP, Thomas DJ, Trulson MO, Vyas KR, Frazer KA, Fodor SP, Cox DR: Blocks of limited haplotype diversity revealed by high-resolution scanning of human chromosome 21 . Science 200I, 294(5547): I7I9-I 723.

17. Hegele RA, Plaetke R, Lalouel JM: Linkage disequilibrium between DNA markers at the low-density lipoprotein receptor gene. Genet Epidemiol 1990, 7(I):69-8I.

18. Jeffreys AJ, Ritchie A, Neumann R: High resolution analysis of haplotype diversity and meiotic crossover in the human TAP2 recombination hotspot. Hum Mol Genet 2000, 9(5):725-733.

19. Jeffreys AJ, Kauppi L, Neumann R: Intensely punctate meiotic recombination in the class II region of the major histocompatibility complex. Nat Genet 200I, 29(2):2I7-222.

20. Zhang K, Akey JM, Wang N, Xiong M, Chakraborty R, Jin L: Randomly distributed crossovers may generate block-like patterns of linkage disequilibrium: an act of genetic drift. Hum Genet 2003, I I3( I):5 I-59.

21. Weggemans RM, Zock PL, Tai ES, Ordovas JM, Molhuizen HO, Katan MB: ATP binding cassette G5 CI950G polymorphism may affect blood cholesterol concentrations in humans. Clin Genet 2002, 62(3):226-229.

22. Chan DC, Watts GF, Barrett PH, Whitfield AJ, van Bockxmeer FM: ATP-binding cassette transporter $\mathbf{G 8}$ gene as a determinant of apolipoprotein B-100 kinetics in overweight men. Arterioscler Thromb Vasc Biol 2004, 24(I I):2 I88-2I9I.

23. Hubacek JA, Berge KE, Stefkova J, Pitha J, Skodova Z, Lanska V, Poledne R: Polymorphisms in ABCG5 and ABCG8 transporters and plasma cholesterol levels. Physiol Res 2004, 53(4):395-40I. 
24. Kajinami K, Brousseau ME, Nartsupha C, Ordovas JM, Schaefer E): ATP binding cassette transporter $G 5$ and $G 8$ genotypes and plasma lipoprotein levels before and after treatment with atorvastatin. J Lipid Res 2004, 45(4):653-656.

25. Kajinami K, Takekoshi N, Brousseau ME, Schaefer EJ: Pharmacogenetics of HMG-CoA reductase inhibitors: exploring the potential for genotype-based individualization of coronary heart disease management. Atherosclerosis 2004, 177(2):219-234.

26. Kajinami K, Brousseau ME, Ordovas JM, Schaefer E): Interactions between common genetic polymorphisms in ABCG5/G8 and CYP7AI on LDL cholesterol-lowering response to atorvastatin. Atherosclerosis 2004, 175(2):287-293.

27. Gylling $\mathrm{H}$, Hallikainen M, Pihlajamaki J, Agren J, Laakso M, Rajaratnam RA, Rauramaa R, Miettinen TA: Polymorphisms in the ABCG5 and ABCG8 genes associate with cholesterol absorption and insulin sensitivity. J Lipid Res 2004.

28. Plat J, Bragt MC, Mensink RP: Common sequence variations in ABCG8 are related to plant sterol metabolism in healthy volunteers. J Lipid Res 2005, 46(I):68-75

29. Miwa K, Inazu A, Kobayashi J, Higashikata T, Nohara A, Kawashiri M, Katsuda S, Takata M, Koizumi J, Mabuchi H: ATP-binding cassette transporter G8 M429V polymorphism as a novel genetic marker of higher cholesterol absorption in hypercholesterolaemic Japanese subjects. Clin Sci (Lond) 2005, I09(2): I 83- 188.

30. Parra EJ, Kittles RA, Argyropoulos G, Pfaff CL, Hiester K, Bonilla C, Sylvester N, Parrish-Gause D, Garvey WT, Jin L, McKeigue PM, Kamboh MI, Ferrell RE, Pollitzer WS, Shriver MD: Ancestral proportions and admixture dynamics in geographically defined African Americans living in South Carolina. Am J Phys Anthropol 200I, I | 4(I): 18-29.

3I. McLean DCJ, Spruill I, Gevao S, Morrison EY, Bernard OS, Argyropoulos $\mathrm{G}$, Garvey WT: Three novel $m$ tDNA restriction site polymorphisms allow exploration of population affinities of African Americans. Hum Biol 2003, 75(2):147-161.

32. Guo SW, Xiong M: Estimating the age of mutant disease alleles based on linkage disequilibrium. Hum Hered 1997, 47(6):315-337.

33. Excoffier L, Slatkin M: Maximum-likelihood estimation of molecular haplotype frequencies in a diploid population. Mol Biol Evol 1995, I2(5):921-927.

34. Stephens M, Smith NJ, Donnelly P: A new statistical method for haplotype reconstruction from population data. Am J Hum Genet 200I, 68(4):978-989.

35. Zhang K, Jin L: HaploBlockFinder: haplotype block analyses. Bioinformatics 2003, 19(10):1300-1301.

36. Hill WG, Weir BS: Maximum-likelihood estimation of gene location by linkage disequilibrium. Am J Hum Genet 1994, 54(4):705-7।4.

37. Lewontin RC: The Interaction of Selection and Linkage. li. Optimum Models. Genetics 1964, 50:757-782.

38. Abecasis GR, Cookson WO: GOLD--graphical overview of linkage disequilibrium. Bioinformatics 2000, 16(2): |82-183.

39. Altshuler D, Brooks LD, Chakravarti A, Collins FS, Daly MJ, Donnelly P: A haplotype map of the human genome. Nature 2005, 437(7063): $1299-1320$.

40. International HapMap Project: [www.hapmap.org].

4I. Akey JM, Zhang K, Xiong M, Jin L: The effect of single nucleotide polymorphism identification strategies on estimates of linkage disequilibrium. Mol Biol Evol 2003, 20(2):232-242.

42. Wilson JF, Weale ME, Smith AC, Gratrix F, Fletcher B, Thomas MG, Bradman N, Goldstein DB: Population genetic structure of variable drug response. Nat Genet 200I, 29(3):265-269.

43. Tishkoff SA, Verrelli BC: Patterns of human genetic diversity: implications for human evolutionary history and disease. Annu Rev Genomics Hum Genet 2003, 4:293-340.

44. Ke X, Hunt S, Tapper W, Lawrence R, Stavrides G, Ghori J, Whittaker P, Collins A, Morris AP, Bentley D, Cardon LR, Deloukas P: The impact of SNP density on fine-scale patterns of linkage disequilibrium. Hum Mol Genet 2004, I 3(6):577-588.

45. Sun $X$, Stephens JC, Zhao H: The impact of sample size and marker selection on the study of haplotype structures. Hum Genomics 2004, I(3): I79-193.

46. Helisalmi S, Hiltunen M, Vepsalainen S, livonen S, Corder EH, Lehtovirta M, Mannermaa A, Koivisto AM, Soininen $\mathrm{H}$ : Genetic variation in apolipoprotein D and Alzheimer's disease. I Neurol 2004, 25 I (8):95I-957.

47. Goldstein DB: Haplotype tagging in pharmacogenetics. Novartis Found Symp 2005, 267:|4-9; discussion 19-30.

48. Lee MH, Lu K, Patel SB: Genetic basis of sitosterolemia. Curr Opin Lipidol 200I, I2(2): I4I-I49.

49. Gordon D, Simonic I, Ott J: Significant evidence for linkage disequilibrium over a 5-cM region among Afrikaners. Genomics 2000, 66(I):87-92.

50. Purcell S, Cherny SS, Sham PC: Genetic Power Calculator: design of linkage and association genetic mapping studies of complex traits. Bioinformatics 2003, I9(I): 149-150.

51. De La Vega FM, Gordon D, Su X, Scafe C, Isaac H, Gilbert DA, Spier EG: Power and sample size calculations for genetic case/control studies using gene-centric SNP maps: application to human chromosomes 6,21 , and 22 in three populations. Hum Hered 2005, 60(I):43-60.

52. Gordon D, Haynes C, Blumenfeld J, Finch SJ: PAWE-3D: visualizing Power for Association with Error in case/control genetic studies of complex traits. Bioinformatics 2005, In Press:

53. Gordon D, Finch SJ, Nothnagel M, Ott J: Power and sample size calculations for case-control genetic association tests when errors are present: application to single nucleotide polymorphisms. Hum Hered 2002, 54(I):22-33.

54. Graf GA, Cohen JC, Hobbs HH: Missense mutations in ABCG5 and ABCG8 disrupt heterodimerization and trafficking. J Biol Chem 2004.

\section{Pre-publication history}

The pre-publication history for this paper can be accessed here:

\section{http://www.biomedcentral.com/1471-2350/7/13/prepub}

Publish with Biomed Central and every scientist can read your work free of charge

"BioMed Central will be the most significant development for disseminating the results of biomedical research in our lifetime. "

Sir Paul Nurse, Cancer Research UK

Your research papers will be:

- available free of charge to the entire biomedical community

- peer reviewed and published immediately upon acceptance

- cited in PubMed and archived on PubMed Central

- yours - you keep the copyright
BioMedcentral 